\title{
SiAlON Ceramics for the High Temperature Applications: High Temperature Creep Behavior
}

\author{
Alper Uludag and Dilek Turan
}

\begin{abstract}
Gas turbine engines have been widely used in electricity power generation in industry and aviation. The performance of gas turbine engines is limited by the temperature and strength capabilities of the materials used in the engine. Silicon nitride based ceramics have been expected to be candidates for gas turbine engine components due to their promising mechanical properties at high temperatures. On this basis, over the last 40 years large number of programs in the world has been working to produce ceramic components for gas turbines with the goals of increasing efficiency and lowering emissions. But there are some difficulties that limit the use of structural ceramics based silicon nitride in gas turbine components. Creep performance is one of those problems and creep performance of a material is one of the major factors for determining its high temperature application. In this study creep behavior of SiAION ceramics, which are solid solutions of silicon nitride ceramics, were investigated at temperatures from $1100{ }^{\circ} \mathrm{C}$ to $1400{ }^{\circ} \mathrm{C}$ under stresses from 50 to $150 \mathrm{MPa}$ in air
\end{abstract}

Index Terms-Advanced ceramics, creep, gas turbine engines, high temperature failures, $\mathrm{SiAlON}$.

\section{INTRODUCTION}

Gas turbine engines have been widely used in power generation in industrial sector and aviation. The development of gas turbine engines and the increase in fuel efficiency depends on the development of high temperature materials with the intended performance. Silicon nitride based ceramics have been expected to be candidates for gas turbine engine components due to their promising mechanical properties at high temperatures. On this basis, over the last 40 years large number of programs has been working to produce ceramic components for gas turbines to increase fuel efficiency and to lower emissions. But there are some difficulties that limit the use of structural ceramics based silicon nitride in gas turbine components. Creep performance is one of those problems and creep performance of a material is one of the major factors for determining its high temperature application [1]-[4].

Service deterioration in gas turbine engine components is inevitable. Therefore, gas turbine components have various life-limiting failure types. Life-limiting failure types are determined by conditions of a component operated in service. Most common life-limiting failure types of gas turbine hot section parts are creep, oxidation, low and high cycle fatigue, and corrosion. For the best efficiency, gas turbines must operate to highest possible temperatures. But the performance of gas turbine engines is limited by the temperature and

Manuscript received July 8, 2014; revised November 20, 2014.

Alper Uludag and Dilek Turan are with Faculty of Aeronautics and Astronautics, Anadolu University, Eskişehir, 26470, Turkey (e-mail: alperuludag@anadolu.edu.tr,dtetik@anadolu.edu.tr). strength capabilities of the materials used in the engine. The endurance of the gas turbine engine components to high temperature conditions mainly depends on the creep resistance of materials. Creep may be defined as a time-dependent deformation at elevated temperature and constant stress, following then, that a failure from such a condition is referred to as a creep failure. The temperature at which creep begins depends on the material composition. The end of useful service life of the high-temperature components are usually failed by a creep [1], [5].

Among components of gas turbine engine turbine blades and sometimes the high pressure stages of compressor blades are subject to creep as a consequence of operating at high temperatures and stresses, and creep is eventually the life-limiting process for all blades so exposed. Blades may elongate and contact the non-rotating components due to creep, and dismantling of the engine for repair and replacement of both blades and non-rotating components would be necessary [6].

Fig. 1 shows a photo of aircraft engine turbine blade on which creep damage observed during routine inspection.

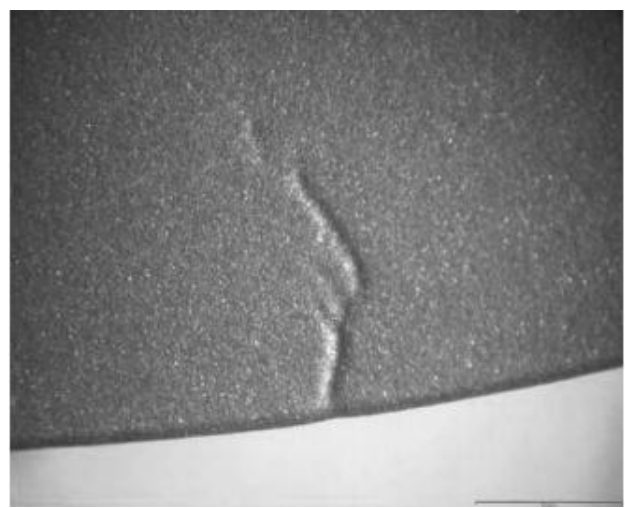

Fig. 1. Creep damage on a blade observed during routine inspection [6].

The high temperature mechanical properties, especially creep, of silicon nitride based ceramics depend on the type and amounts of sintering additives used in the processing of these materials [4], [7].

During sintering, additives such as yttrium or rare earth oxides (with alumina) react with surface oxides on the silicon nitride particles and some of the nitride itself to form a $\mathrm{M}-\mathrm{Si}$-(Al)-O-N liquid ( $\mathrm{M}=\mathrm{Y}$ or $\mathrm{Ln}$ ) which on cooling remains as a glass, located both at grain triple points and as intergranular films [3], [8]. The presence of these amorphous grain boundary phases in the grain boundaries and triple junctions results in beneficial effects to the mechanical properties at ambient temperatures. Higher strength and toughness are obtained as a consequence of the acicular grain growth and the reduction of the inherent flaw size. But at 
temperatures exceeding the softening point of the amorphous phase (about $1000{ }^{\circ} \mathrm{C}$ ), mechanical properties of the material such as creep and oxidation resistance degrades rapidly.

Because of their insufficient thermal and chemical resistance at high temperatures, the amorphous grain-boundary phase significantly influences the lifetime-determining properties, such as creep, subcritical crack growth, and oxidation resulting in accelerated failure of the material. Therefore the intergranular phase (especially if glassy) is critically important in determining the mechanical and chemical properties of silicon nitride based ceramics particularly at high temperature. It has been observed during the last 25 years by many researchers that the onset of creep deformation and degradation of strength in such materials can be significantly reduced or even eliminated by decreasing the amount of intergranular glassy phase or by modifying it to produce more refractory crystalline phases [9].

One promising way for decreasing the amount of glassy intergranular phase in dense silicon nitride ceramics or lessen its effect on high temperature properties is by the fabrication of SiAlON materials. The family of $\mathrm{Si}_{3} \mathrm{~N}_{4}$ solid solutions containing $\mathrm{Al}_{2} \mathrm{O}_{3}$ along with other metal oxides is termed SiAlONs [10]. In this study creep behavior and high temperature mechanical properties of SiAlON ceramics were investigated at temperatures from $1100{ }^{\circ} \mathrm{C}$ to $1400{ }^{\circ} \mathrm{C}$ under stresses from 50 to $150 \mathrm{MPa}$ in air by laboratory creep tests.

\section{EXPERIMENTAL PROCEDURE}

The creep test is intended to evaluate the deformation of a test piece under nominally constant stress as a function of time at elevated temperatures. In particular it can be used for materials comparison, or for determining the temperature at which creep deformation becomes significant for a prospective engineering use. The four point bending creep method involves supporting a bar test piece on two supports near its ends, heating it to the required elevated temperature which is maintained constant, applying a force to two loading points spaced symmetrically between the support points, and recording the deflection of the test bar with time [11].

Test bar shall be greater than or equal to $45 \mathrm{~mm}$ in length, 4,0 $\pm 0,2 \mathrm{~mm}$ wide and 3,0 $\pm 0,2 \mathrm{~mm}$ thick (Fig. 2).

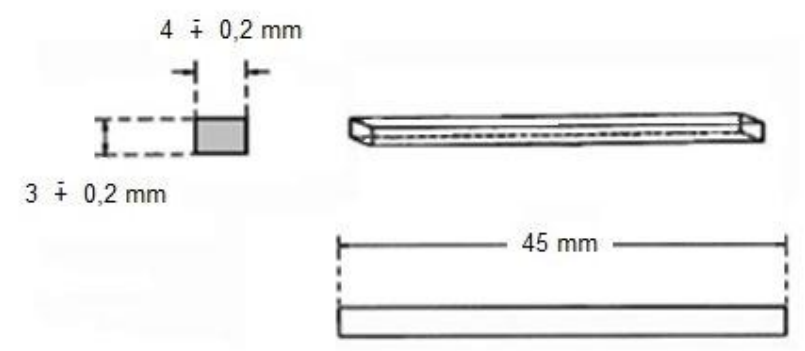

Fig. 2. Dimensions and geometry of a creep test specimen.

Experimental procedure consists of producing of creep test specimens from powders by different methods such as milling, pressing, sintering and grinding then creep testing of specimens and analyzing of test results and microstructural characterization of non-crept and the crept samples.

\section{A. Production of Creep Test Material}

The overall composition of the prepared starting powder mixtures corresponded to duplex $\alpha / \beta$ SiAlON ceramic with 25 $\alpha / 75 \beta$ ratio. Starting powder mixtures were prepared by $\alpha-S i 3 N 4$ (UBE-E10) with AlN (HC Starck-Berlin, Grade C), $\mathrm{Al}_{2} \mathrm{O}_{3}$ (Alcoa, Grade A16SG) together with mixtures of the oxides of $\mathrm{Y}, \mathrm{Sm}$ and $\mathrm{Ca}$ as densifying additives. Powder mixtures were prepared by wet milling in isopropyl alcohol using $\mathrm{Si}_{3} \mathrm{~N}_{4}$ media. The slurries were then dried in a rotary evaporator and sieved down to $250 \mu \mathrm{m}$. The powders were uniaxially pressed under $50 \mathrm{MPa}$ and subsequently cold isostatically pressed at $300 \mathrm{MPa}$ to improve green density. The bar specimens were gas pressure sintered, followed by post sintering heat treatment under $\mathrm{N}_{2}$ atmosphere at different times and temperatures. The densities of the sintered bodies, measured by the water-displacement method, were $>99.9 \%$ of their theoretical value. The creep test specimens were first machined by surface grinding in a direction parallel to the length of the specimens with 80-350 grit diamond resinoid bonded wheels. They were then mechanically polished and the edges of all specimens were chamfered.

\section{B. Creep Testing of Specimens}

Creep tests were conducted on four-point bending fixture (as shown in Fig. 3) made of SiC with inner and outer span of $20 \mathrm{~mm}$ and $40 \mathrm{~mm}$, respectively by using of an Instron 5581 testing machine.

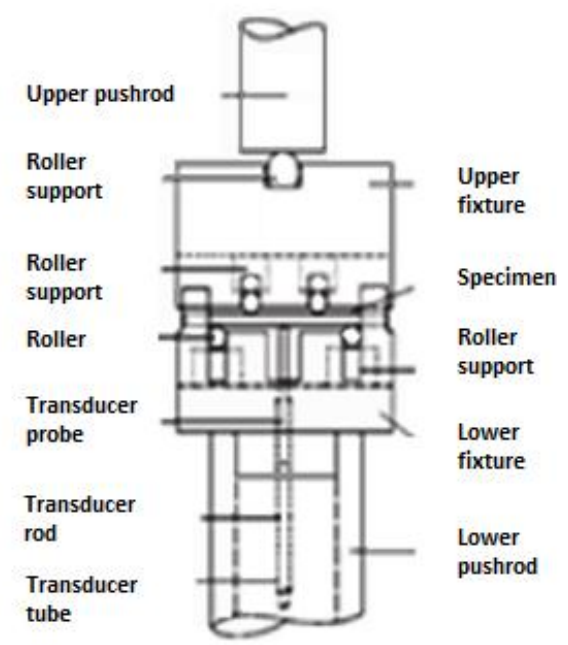

Fig. 3. Schematic representation of bending creep testing fixture.

Test specimens were nominally $3 \mathrm{~mm}$ in height, $4 \mathrm{~mm}$ in width, and $50 \mathrm{~mm}$ in length. The fixture assembly with mounted specimen was then placed between two rigid $\mathrm{SiC}$ supports connected to the Alumina push rods of the creep tester. An initial preload of $20 \mathrm{~N}$ was applied to the specimen and maintained until the actual testing load applied. The specimens were heated by molybdenum disilicate elements in the furnace and a $\mathrm{Pt}-\mathrm{Rh}$ thermocouple was used to monitor the temperature through a programmable controller, which offered $\pm 1{ }^{\circ} \mathrm{C}$ of temperature control. The temperature increased at a rate of about $5{ }^{\circ} \mathrm{C}$ per minute, and the system was held at given temperature for 0.5 hour before loading. The creep strain of the outer fiber surface of the creep specimen was measured by transducer rod connected to a 
linear-variable differential transducer (LVDT) and recorded by a personal computer.

\section{Microstructural Characterization}

In order to find out the role of microstructure on the creep resistance of $\mathrm{SiAlON}$ ceramics, the interfacial microstructures of sintered and crept samples were investigated by using scanning electron microscope (SEM-Zeiss $50 \mathrm{VP}$ ).

\section{RESULTS AND DISCUSSION}

Creep tests are normally performed by applying a constant load/stress and measuring the strain as a function of time. Whereas metallic materials are normally tested in uniaxial tension, the difficulty in producing tensile ceramic specimens, creep data for ceramics are often collected in compression or bending (Fig. 4).

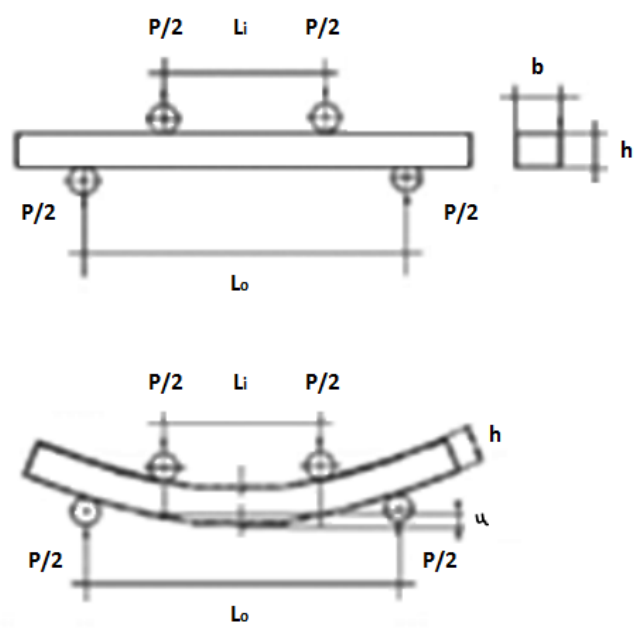

Fig. 4. Bending creep testing method.

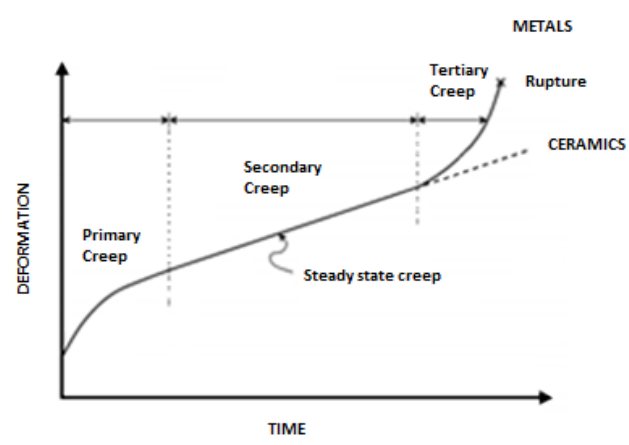

Fig. 5. Creep curves for metallic and ceramic materials.

Therefore, in this study bending creep tests were conducted with specimens in order to find out creep resistance of SiAlON ceramics, in air at temperatures ranging between 1100 and $1400^{\circ} \mathrm{C}$ and under stress levels ranging from 50 to $150 \mathrm{MPa}$. A classic creep curve displays three regions corresponding to primary, secondary, and tertiary creep. After an initial elastic deformation upon application of the load, the primary creep regime is characterized by a decreasing creep rate, indicating some increasing resistance to deformation. An approximately constant creep rate occurs during the secondary or steady-state creep regime. During the tertiary stage, there is an increase in the creep rate leading ultimately to failure. Many ceramics do not demonstrate the idealized three-stage creep behavior, they show primary and secondary region (Fig. 5) [12].

Total duration of creep tests can vary depending upon test conditions such as testing temperature, magnitude of applied stresses, materials and purpose of testing. In this study, some of creep tests were finished after 24 hours and some of them were finished after 72 hours, without evidence of rupture or macroscopic failure. The bending creep strain - time curves obtained in this study is presented in the in Fig. 6 and Fig. 7.

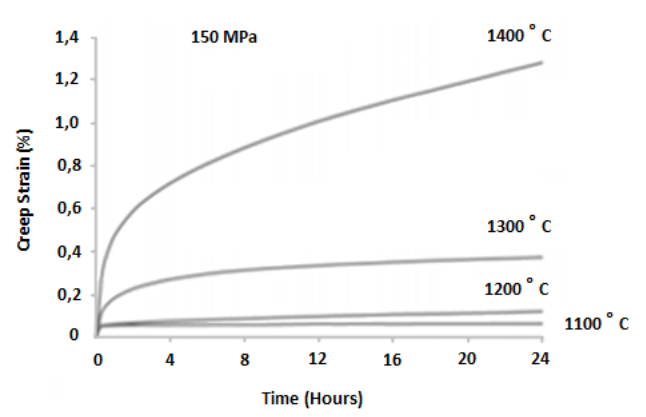

Fig. 6. Creep behavior of SiAlON as a function of temperature.

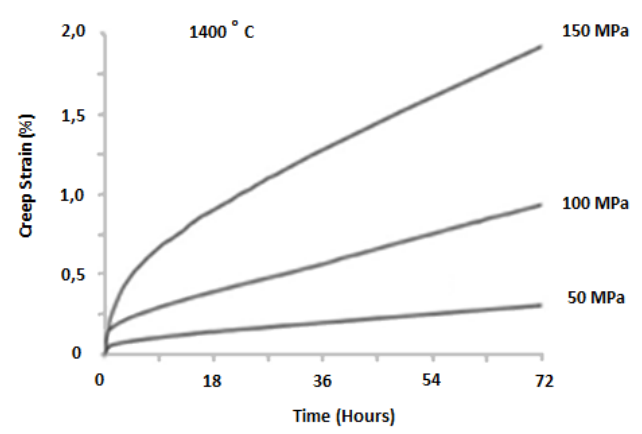

Fig. 7. Creep behavior of SiAlON as a function of stress.

The time for primary creep is between 5-30 hours depending on the testing condition. The primary creep was followed by a steady state, nearly constant, creep rate. In secondary creep the strain rate was relatively low, but the specimens especially at $1400^{\circ} \mathrm{C}$ temperature deformed most in this stage; about $60-70 \%$ of the total deformation occurred.

All the measured flexure creep strain-time curves show primary and secondary creep, but no tertiary creep. $\mathrm{Si}_{3} \mathrm{~N}_{4}$ based ceramics typically show only primary and secondary creep [13]-[15]. Stress rupture occurs in the secondary creep region because of the relatively brittle nature of Si3N4 based ceramics.

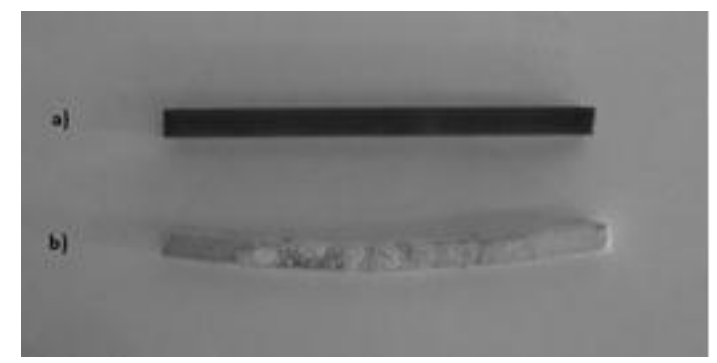

Fig. 8. Photos of a sintered specimen (a), and a crept specimen (b).

Photos of a typical sintered specimen and crept specimen 
are shown in Fig. 8. This specimen crept more than $1.5 \%$ strain. The color of the specimens changed from dark brown to almost white after creep tests. This color change is typical of this material at high temperatures, e.g. $>1200{ }^{\circ} \mathrm{C}$ for long times in an oxidizing atmosphere. Visual observation of crept specimen surfaces reveals oxidation related effects.

The general microstructure of sintered SiAlON composite investigated consists of $\alpha$-SiAlON, $\beta$-SiAlON grains, and triple-junction pockets filled with remains of the liquid formed during sintering either in amorphous or crystalline form. Fig. 9 shows the back-scattered SEM image of as received $\alpha / \beta-S i A 1 O N$ composite.

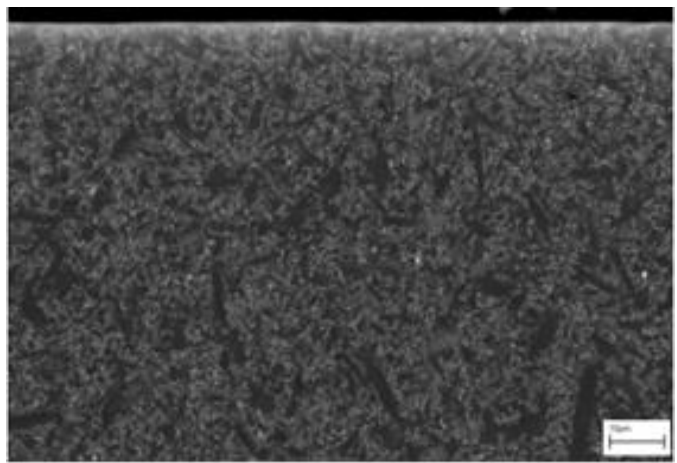

Fig. 9. Back-scattered SEM image of sintered SiAlON composite

This back scattered image very clearly distinguish between the various phases; $\beta$-SiAlON grains, which contain no rare earth element are black colored and more needle like, whereas $\alpha$-SiAlON grains, which contain small amount of rare earth element, are grey colored and more equiaxed whilst rare earth rich glassy or crystalline phases appear fine grained and white colored, because of high rare earth content.

Fig. 10 demonstrates the back-scattered SEM image of a cross section cut from the crept sample shows the surface of oxidation scale. Several sub-layers resulted from oxidation can be visually distinguished on cross section in Fig. 10.

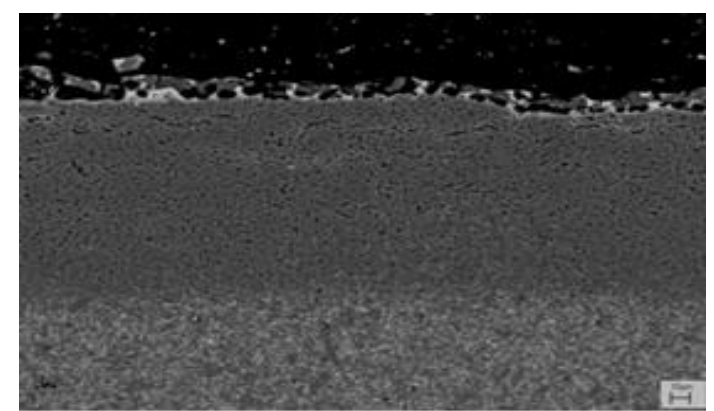

Fig. 10. Back-scattered SEM image of crept SiAlON composite.

SiAlONs generally consist of two crystalline phases: $\alpha$-SiAlON and $\beta$-SiAlON which are isostructural with $\alpha-$ Si3N4 and $\beta$-Si3N4, respectively [16].

An important advantage of a-SiAlONs is that the amount of intergranular phase is reduced by the transient liquid phase being absorbed into the matrix of $\alpha$-SiAlON phase during sintering. As $\alpha$-SiAlON and $\beta$-SiAlON phases are completely compatible, SiAlON ceramics with both higher hardness and higher toughness can be achieved through designing of $\alpha / \beta-S i A l O N$ composites [17]. Meanwhile, the combination of SiAlON phases has a great influence on mechanical properties of SiAlON ceramics. Due to the different microstructure and composition, $\alpha$ and $\beta$-SiAlON have distinct contribution to creep resistance [10], [18].

The two common methods for improving high-temperature properties of $\mathrm{Si} 3 \mathrm{~N} 4$ based ceramics are i) increasing the softening point of the amorphous phases above the temperature range to which the ceramic will be exposed and ii) crystallization of the amorphous phases, so as to eliminate the softening point entirely [9].

Therefore, one of the main aspects in designing SiAlONs with improved high temperature properties would be to use additives that would provide a good liquid phase sintering behavior and at the same time would crystallize well to refractory phases after sintering. In this study, multi cation system was chosen to produce hard and tough a/b-SiAlON composite for high temperature applications [19].

\section{CONCLUSION}

The creep test is usually employed to determine the creep performance of materials. Engineers need to account for this expected deformation when designing systems especially when new materials intended to be used. The creep behavior of SiAlON ceramic with was assessed by four-point bending creep tests at temperatures from $1100{ }^{\circ} \mathrm{C}$ to $1400{ }^{\circ} \mathrm{C}$ under stresses from 50 to $150 \mathrm{MPa}$ in air.

The SiAlON system presents numerous opportunities for further development. The presence of a number of crystalline secondary phases forming in the system can be utilized for the improvement of high temperature properties. However, more understanding is needed on the effect of dopant type and composition in order to obtain better crystallization and improved grain boundary chemistry for creep behavior of these ceramics.

\section{ACKNOWLEDGMENT}

We would like to thank MDA Advanced Ceramic Technology A.Ş., for supplying of SiAlON composites, Dr. Hilmi Yurdakul for his help on microscopy investigations and Prof. Dr. Servet Turan for useful discussions.

\section{REFERENCES}

[1] G. W. Meetham and D. V. Van, Materials for High Temperature Engineering Applications, Berlin, Springer, 2000.

[2] M. H. Bocanegra-Bernala and B. Matovic, "Dense and near-net-shape fabrication of $\mathrm{Si}_{3} \mathrm{~N}_{4}$ ceramics," Materials Science and Engineering, vol. 500, pp. 130-149, 2009.

[3] S. Hampshire and M. Pomeroy, "Oxynitride glasses and their properties - Implications for high temperature performance of silicon nitride-based ceramics," Key Engineering Materials, vol. 317-318, pp 419-424, 2006.

[4] M. H. Bocanegra-Bernala and B. Matovic, "Mechanical properties of silicon nitride based ceramics and its use in structural applications at high temperatures," Mater. Sci. Eng., A 527, pp. 1314-1338, 2010.

[5] R. W. Evans and B. Wilshire, Introduction to Creep, London: IOM Communications, 1993.

[6] T. J. Carter, "Common failures in gas turbine blades," Engineering Failure Analysis, vol. 12, pp. 237-247, 2005

[7] S. Hampshire, "Silicon nitride ceramics," Mater. Sci. Forum, vol. 606 pp. 27-41, 2009.

[8] S. Hampshire and M. J. Pomeroy, "Effect of composition on viscosities of rare earth oxynitride glasses," Journal of Non-Crystalline Solids, vol. 344, pp. 1-7, 2004. 
[9] H. Mandal, D. P. Thompson, and T. Ekstrom, "Optimization of SiAlON ceramics by heat treatment," Third Euro-Ceramics, vol. 3, pp. 385-390, 1993

[10] K. M. Fox and J. R. Hellmann, "Microstructure and creep behavior of silicon nitride and SiAlONs," Int. J. Appl. Ceram. Technol., vol. 5, pp. $138-154,2008$.

[11] ENV 820-1, "Advanced technical ceramics - Methods of testing monolithic ceramics - Thermomechanical properties - Part 1: Determination of flexural strength at elevated temperatures," 2002.

[12] M. H. Lewis and R. S. Dobedoe, Creep of Ceramics, Encyclopedia of Materials: Science and Technology, 2002.

[13] A. A. Wereszczak, M. K. Ferber, T. P. Kirkland, A. S. Barnes, E. L. Frome, and M. N. Menon, "Asymmetric tensile and compressive creep deformation of hot-isostatically-pressed $\mathrm{Y}_{2} \mathrm{O}_{3}$-doped-Si ${ }_{3} \mathrm{~N}_{4}, "$ J. Eur. Ceram. Soc., vol.19, pp. 227-237, 1999.

[14] G. Ziegler, "Thermo-mechanical properties of silicon nitride and their dependence on microstructure," Mater. Sci. Forum, vol. 47, pp. 162-203, 1989.

[15] J. J. Melendez Martinez and A. Dominguez-Rodriguez, "Creep of silicon nitride," Prog. Mater. Sci., vol. 49, pp. 19-107, 2004.

[16] S. Hampshire, H. K. Park, D. P. Thompson, and K. H. Jack, " $\alpha$-SiAlON ceramics," Nature, vol. 274, pp. 880-882, 1978.

[17] H. Mandal, "New developments in $\alpha$-SiAlON ceramics," J. Eur. Ceram. Soc., vol. 19, no. 13-14, pp. 2349-2357, 1999.
[18] H. Klemm, M. Herrmann, T. Reich, and C. Schubert, "High-temperature properties of mixed $\alpha / \beta-S i A l O N$ materials," $J$. Am. Ceram. Soc., vol. 81, no. 5, pp. 1141-1148, 1998.

[19] N.C. Acikbas, A. Kara, S. Turan, F. Kara, H. Mandal and B. Bitterlich, "Influence of type of cations on intergranular phase crystallisation of SiAlON ceramics," Mater. Sci. Forum, vol. 554, pp. 119-122, 2007.

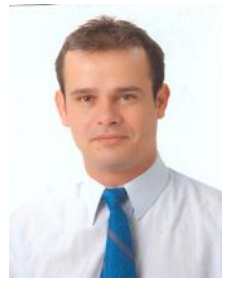

Alper Uluda $\breve{g}$ was graduated from the Department of Airframe and Powerplant Maintenance at the Faculty of Aeronautics and Astronautics, Anadolu University in 1999. He received the master degree and $\mathrm{PhD}$ degree in civil aviation from Anadolu University in 2003 and 2010 respectively. He became an assistant professor in 2012. He conducted researches on high temperature behavior of advanced ceramics. His current research interests are gas turbines, energy and high temperature materials, sustainability in aviation. He has been giving courses at Faculty of Aeronautics and Astronautics, Anadolu University, Eskisehir since 2012. 